\title{
Exploração, gênero e circuitos sul-americanos nos processos de expulsão de estrangeiros (1907-1920)
}

\section{Cristiana Schettini ${ }^{2}$}

Este artigo aborda uma variedade de relações estabelecidas entre homens e mulheres suspeitos de envolvimento com a exploração da prostituição por meio de processos de expulsão de estrangeiros no começo do século XX. As dimensões transnacionais de suas vidas, em especial seus deslocamentos entre Argentina e Brasil, são fundamentais para entender as estratégias de sobrevivência e as margens de ação.

Palavras-chave: Proxenetismo, expulsão de estrangeiros, prostitutas.

\section{Exploration, gender, and South American circuits in the processes of expulsion of foreigners (1907-1920)}

Through records of expulsion of foreigners, this article discusses a myriad of relationships established between men and women that were suspect of involvement in the exploitation of prostitution. I argue that the transnational dimension of lives of women identified as victims of pimps in their voyages between Argentina and Brazil, is crucial to understand their strategies of survival and social networks.

Keywords: Pimping, expulsion of foreigners, prostitutes.

1 Artigo recebido em 10.2.2012 e aprovado para publicação em 26.5.2012.

2 Instituto de Altos Estudios Sociales, Universidad Nacional de General San Martín (Idaes-Unsam). Pesquisadora do Consejo Nacional de Investigaciones Científicas y Tecnológicas, com sede no Instituto Interdisciplinario de Estudios de Género, Universidad de Buenos Aires (Conicet-IIEGEUBA).E-mail: cschettini@hotmail.com 


\section{Exploration, genre, et Sud américains circuits dans le processus d'expulsion d'étrangers (1907-1920)}

Cet article décrit une variété de relations entre les hommes et les femmes soupçonnées d'implication dans l'exploitation de la prostitution à travers le processus d'expulsion des étrangers dans le début du $\mathrm{XX}^{\mathrm{e}}$ siècle. Les dimensions transnationales de leur vie, en particulier de leurs voyages entre l'Argentine et le Brésil, sont fondamentales pour la compréhension des stratégies de survie et les marges d'action.

Mots-clés: Proxénétisme, expulsion des étrangers, prostitueés.

Este artigo discute uma variedade de relações estabelecidas entre certos grupos de homens e mulheres, suspeitos de envolvimento com a exploração do comércio sexual, que viveram em cidades brasileiras e argentinas no começo do século XX. Para isso, analiso as investigações policiais que foram realizadas entre 1907 e 1920 para fundamentar as expulsões de estrangeiros do Brasil acusados de caftismo, em particular daqueles que passaram previamente pela Argentina. Essa documentação, que em princípio nos informa mais sobre as obsessões e manias policiais que sobre a experiência do comércio sexual internacional, também pode ser lida para sugerir algumas dimensões da experiência social de homens e mulheres que serviram de testemunhas, que foram vítimas ou que foram acusados de ser exploradores de prostitutas, principalmente os significados que atribuíam à ideia de exploração.

A acusação da exploração sexual de uma mulher, em especial quando envolvia o deslocamento por fronteiras nacionais, era uma ideia simbolicamente poderosa nos primeiros anos do século XX: a ampla circulação de terríveis histórias de tráfico de mulheres, nas quais jovens europeias eram enganadas e levadas a cidades portuárias da América do Sul, onde eram obrigadas a prostituir-se, provava seu forte apelo naquele momento. Essas histórias podiam ser escutadas e lidas em muitas cidades dos dois lados do oceano Atlântico, mas tinham significados bem locais: na Inglaterra, podiam funcionar como histórias morais, de advertência, para jovens trabalhadoras desejosas de uma vida nova do outro lado do oceano; no Brasil, a imagem de "escravas brancas" remetia ao intenso debate sobre a reorganização das relações de trabalho desde os fins do século XIX; na Argentina, a ideia de uma rede de traficantes de mulheres mobilizava temores criados pelas 
dimensões inéditas que ganhavam a imigração de mão de obra europeia e seu impacto na definição de conceitos como cidadania e nação. ${ }^{3}$

Em outra oportunidade, argumentei que as histórias de exploração sexual de mulheres registradas em processos criminais de lenocínio e na documentação de expulsão de estrangeiros revelam diversos aspectos das experiências de mulheres dedicadas ao comércio sexual no começo do século XX, tal como arranjos de moradia, condições de trabalho e relações amorosas. ${ }^{4}$ Neste artigo, a intenção é enfocar a conexão entre as estratégias de sobrevivência e a vida amorosa de homens e mulheres que viveram entre cidades brasileiras e argentinas. A documentação de expulsão registra suas vidas em movimento, o que abre a possibilidade de se reconsiderarem os sentidos de seus movimentos migratórios em perspectivas pouco exploradas pela história social. ${ }^{5}$

Durante muito tempo, a historiografia brasileira e a argentina trataram as leis de expulsão de estrangeiros de uma maneira similar àquela como foram tratadas pelos contemporâneos, em especial pelos militantes operários que as sofreram na pele: como iniciativas ilegais e autoritárias de governos que dependiam de estados de sítio, sustentados por uma polícia com ampla esfera de ação para reprimir os combativos movimentos sociais que caracterizaram o começo do século XX na região. Há suficientes evidências de que essa legislação tinha um componente arbitrário em sua concepção e que foi efetivamente empregada de forma discricionária e autoritária nos dois países. Mas também é possível considerar que a prática da legislação de expulsão teve usos e resultados imprevistos, que merecem ser mais interrogados. Assim, recentemente, tanto no Brasil quanto na Argentina, novos estudos começaram a empregar as leis e sua prática para formular novas

3 SCHETTINI, Cristiana. "Que tenhas teu corpo": uma história das políticas da prostituição no Rio de Janeiro das primeiras décadas republicanas. Rio de Janeiro: Arquivo Nacional, 2006; WALKOWITZ, Judith. City of dreadful delight: narratives of sexual danger in Late-Victorian London. Chicago: University of Chicago Press, 1992; GUY, Donna. El sexo peligroso: la prostitución legal en Buenos Aires, 1875-1955. Buenos Aires: Sudamericana, 1994.

4 SCHETTINI, Cristiana. "Que tenhas teu corpo". Op. cit., especialmente cap. 3.

5 Nesse aspecto, este artigo se alimenta do grande interesse de historiadores e historiadoras do trabalho na América Latina ao longo das últimas décadas pelas possibilidades de repensar nossas próprias definições de trabalho à luz de uma perspectiva de gênero para analisar os conflitos sociais e as desigualdades que envolveram homens e mulheres no passado. Para um desenvolvimento desse ponto, ver os artigos e a apresentação do dossiê "Perspectivas de gênero nos mundos do trabalho", organizado por Fabiane Popinigis e a autora, na revista Mundos do Trabalho, v. 1, n. 2, 2009. 
perguntas: sobre sua participação na definição dos contornos da cidadania, sobre a experiência de outros grupos sociais que também terminaram sendo afetados por seu caráter arbitrário e inclusive sobre os conflitos entre o Poder Executivo e o Judiciário. Todas elas terminaram tendo alguma influência na construção social da figura do "indesejável".

Seguindo essa tendência, este artigo se pergunta sobre as práticas da lei de expulsão de estrangeiros no contexto brasileiro, associando-as à circulação de certos grupos de homens e mulheres entre ambos os países. As histórias de tráfico de mulheres tendiam a reduzir uma multiplicidade de dimensões transnacionais das vidas das mulheres envolvidas na prostituição a uma única, definida pela associação unívoca entre imigração e exploração. Nesse caso, a intenção é centrar o foco exatamente nos complexos pontos de contato entre suas viagens e a noção de exploração tal como articulada no âmbito dos inquéritos policiais que levaram à expulsão.

Na primeira parte do artigo, enfoco como a legislação de expulsão foi discutida na Argentina e no Brasil. Em um segundo momento, atento para as histórias e relações registradas na investigação policial para fundamentar a expulsão de um estrangeiro que passou pela Argentina antes de vir ao Brasil. Com isso, a intenção é contribuir para relativizar a associação amplamente difundida entre deslocamento de mulheres envolvidas no trabalho sexual e tráfico. Nesse sentido, é a própria noção de exploração articulada por parte dos protagonistas dessas histórias em seus deslocamentos que passa a ocupar o centro do problema.

\section{As leis de expulsão na Argentina e no Brasil}

A partir de finais do século XIX, as cidades de Buenos Aires e do Rio de Janeiro estiveram fortemente conectadas pela intensificação da circulação de gente, capital, ideias e produtos. Em particular, as viagens de homens e mulheres europeus foram objeto de interesse da história social. Estudos sobre a classe tra-

6 Destacam-se VILLAVICENCIO, Susana (Ed.). Los contornos de la ciudadanía. Nacionales y extranjeros en la Argentina del centenario. Buenos Aires: Eudeba, 2003; MENEZES, Lená Medeiros de. Os indesejáveis. Rio de Janeiro: EdUERJ, 1996; BONFÁ, Rogerio Giampetro. Com lei ou sem lei: as expulsões de estrangeiros e o conflito entre o Executivo e o Judiciário na Primeira República. Tese (Mestrado em História) - Instituto de Filosofia e Ciências Humanas, Universidade Estadual de Campinas, Campinas, 2008. Ver, também, BONFÁ, Rogerio Giampetro. Com lei ou sem lei: as expulsões de estrangeiros na primeira república. Cadernos AEL, v. 14, n. $26,2009$. 
balhadora de ambos os países trataram-nas principalmente em sua relação com a militância e a organização política da classe. ${ }^{7}$ Já a dimensão de gênero dessas viagens e a experiência de outros grupos de imigrantes menos organizados politicamente foram abordadas por parte da história cultural e dos estudos sobre a sexualidade. Alguns desses estudos chamaram a atenção para o fato de que a imigração associada ao comércio sexual corria sempre o risco de ser entendida como tráfico de mulheres. ${ }^{8} \mathrm{Na}$ historiografia sobre a América do Sul, assim, as dimensões coercitivas das experiências imigratórias foram mais pensadas em termos da imigração feminina que da imigração masculina.

Ao enfrentar a crescente circulação internacional de homens e mulheres suspeitos de explorar o comércio sexual, a polícia carioca e a portenha produziram, desde os fins do século XIX, variada documentação que registrava sua preocupação e seus temores, mas também indícios da experiência social de muitos grupos de estrangeiros. Entre registros rotineiros de prisões, inquéritos e diferentes medidas administrativas, destacava-se a prática da expulsão de estrangeiros.

De fato, uma grande quantidade dos estrangeiros que terminaram expulsos da Argentina e do Brasil a partir da aprovação da Lei de Residência, em 1902, e da Lei Gordo, em 1907, foi acusada de ser anarquista e de cáften, mas também eles enfrentaram a acusação de vagabundos, vigaristas e ladrões. A leitura contrastada entre a documentação de expulsão produzida nos dois países chama a atenção para os mecanismos de acusação. Como se acusa, como se comprova a acusação, enfim, como se cria um indesejável na Argentina e no Brasil? Foi só muito recen-

7 Além dos trabalhos no campo dos estudos imigratórios, ver o clássico de MARAM, Sheldon Leslie. Anarquistas, imigrantes e o movimento operário brasileiro, 1890-1920. Rio de Janeiro: Paz e Terra, 1979. Entre os estudos recentes que enfocam os deslocamentos internacionais de trabalhadores e militantes no período, ver ROMANI, Carlo. Oreste Ristori: uma aventura anarquista. São Paulo: Annablume/Fapesp, 2002; TOLEDO, Edilene. Travessias revolucionárias: idéias e militantes sindicalistas em São Paulo e na Itália (1890-1945). Campinas: Unicamp, 1994; e OLIVEIRA, Vitor Wagner Neto de. Nas águas do Prata: os trabalhadores da rota fluvial entre Buenos Aires e Corumbá (1910-1930). Campinas: Unicamp, 2009.

8 Ver, por exemplo, RAGO, Margareth. Os prazeres da noite. São Paulo: Paz e Terra, 1991; MENEZES, Lená Medeiros de. Os estrangeiros e o comércio do prazer nas ruas do Rio (1890-1930). Rio de Janeiro: Arquivo Nacional, 1992; GUY, Donna. El sexo peligroso: la prostitución legal en Buenos Aires, 1875-1955. Buenos Aires: Sudamericana, 1994; e TROCHON, Yvette. Las rutas de Eros. La trata de blancas en el Atlántico Sur. Montevideo: Taurus, 2007. A perspectiva que identifica tráfico e prostituição é amplamente empregada por abordagens da prostituição atual, tendo sido discutida por muitos estudos antropológicos. Sobre isso, ver PISCITELLI, Adriana. Apresentação. Cadernos Pagu, Campinas, n. 31, p. 9-28, jul./dez. 2008. 
temente que esse tipo de pergunta começou a ser formulado pelas historiografias dos dois países. Até pouco tempo atrás, a legislação de expulsão de estrangeiros foi considerada apenas como um sintoma a mais da crescente repressão ao movimento operário, em um processo marcado pelas arbitrariedades do Poder Executivo. O contraste entre a legislação e os procedimentos de expulsão no Brasil e na Argentina, no entanto, joga outra luz sobre o processo de legitimação da expulsão em cada contexto.

Nos debates parlamentares sobre as leis na Argentina e no Brasil, era evidente o temor provocado pela figura do anarquista estrangeiro, que corporificava o "outro" da nação, devendo ser extirpado. ${ }^{9}$ Tal como ocorria em muitos outros países naqueles anos, a expulsão de estrangeiros como medida administrativa do Poder Executivo foi debatida em meio a discussões mais gerais sobre a cidadania e a nação. Por isso mesmo, essas legislações provocaram recorrentes polêmicas, tendo sido rediscutidas com frequência. Certamente, a eficácia da criação da figura do estrangeiro inimigo da nação contribuiu para sua vigência por muito tempo, mesmo em meio a tantos questionamentos. Nos dois casos, assim, os debates sobre a legislação expressaram posições polarizadas entre o caráter liberal das constituições nacionais vigentes, os direitos individuais e as garantias do processo judicial regular, por um lado, e, por outro, a noção de bem comum, de interesse coletivo e a capacidade do Poder Executivo de reagir rápida e eficazmente diante de um perigo internacional de dimensões desconhecidas.

De fato, as semelhanças entre os casos argentino e brasileiro eram muitas, e os parlamentares recorreram a elas de diferentes maneiras. ${ }^{10}$ No Brasil, por

9 La lei argentina de residência foi aprovada em 1902. Ver SURIANO, Juan. Trabajadores, anarquismo y Estado represor: de la ley de Residencia a la ley de Defensa Social (1902-1910). Buenos Aires: Centro Editor de América Latina, 1988; ZIMMERMANN, Eduardo. Los liberales reformistas. La cuestión social en la Argentina. Buenos Aires: Sudamericana/U. San Andrés, 1995; VILLAVICENCIO, Susana (Ed.). Los contornos de la ciudadanía. Iaacov Oved apresenta um detalhado panorama dos desafios do movimento anarquista e do recrudescimento dos conflitos sociais em El trasfondo histórico de la ley 4144, de Residencia. Desarrollo Económico, v. 16, n. 61, p. 123-150 1976. A lei brasileira foi aprovada em 1907. Ver MENEZES, Lená Medeiros de. Os indesejáveis, p. 183-187. Ao analisar os debates argentinos, Nora Wolfzun ressalta a referência de Miguel Cané, autor da lei, ao estrangeiro como uma planta que deve ser arrancada pela raiz, e a do deputado Ferrer sobre o anarquista como um tigre, "una fieracon forma humana". El extranjero real, un híbrido entre tigre y planta. In: VILLAVICENCIO, Susana (Ed.). Los contornos de la ciudadanía, p. 153-176.

10 Rogério Luis Giampetro Bonfá argumenta que os dois contextos sociais fundamentavam um diálogo constante entre os contemporâneos, em "Com lei ou sem lei”, p. 119. 
exemplo, o caso argentino se transformou em contraponto natural quando a lei de expulsão vigente desde 1907 voltou ao parlamento em 1912 para a discussão do tempo de residência como condição para a expulsão do estrangeiro. $\mathrm{O}$ deputado Adolfo Gordo, autor da lei de 1907, pensava que a inspiração belga da lei de expulsão brasileira terminava concedendo garantias demais para os estrangeiros. De acordo com a lei, o estrangeiro indesejável não podia ser expulso se estivesse casado com uma brasileira, se tivesse filhos brasileiros e, principalmente, ponto que provocou as maiores polêmicas, se vivesse no país há mais de dois anos. Diante dos exemplos dos "países mais civilizados do mundo", que "não fazem as restrições constantes da nossa lei", o Brasil terminaria em "situação de inferioridade". ${ }^{11} \mathrm{O}$ deputado Gordo não se referia a qualquer país civilizado. Os exemplos de Holanda e Bélgica não serviriam tanto, já que eram países que punham muitas dificuldades para a naturalização de estrangeiros e que contavam com uma baixa proporção de estrangeiros em relação aos nacionais. O melhor exemplo para o Brasil era outro:

A República Argentina, que, mesmo antes de decretar qualquer lei em relação ao assunto e não obstante sua Constituição Política assegurar os benefícios da liberdade a todos os homens do mundo que queiram habitar o solo argentino, e garantir-lhes o direito de entrar, permanecer, transitar e sair livremente do território, já fazia expulsões [em 1884] [...]. ${ }^{12}$

Ao contrário da Bélgica, a vizinha Argentina contava com uma Constituição que garantia amplas liberdades aos estrangeiros, era um país dependente da mão de obra imigrante e vítima da agitação anarquista. $\mathrm{O}$ deputado Gordo atribuía à lei de residência argentina, da qual leu alguns trechos, a "estúpidos atentados anarquistas em uma igreja da capital, no Teatro Colón e depois do assassinato do chefe de polícia", misturando acontecimentos de 1901, de 1909 e de 1910, que passaram a ser vistos como causas da lei aprovada em $1902 .{ }^{13}$ A confusão de

11 GORDO, Adolpho. A expulsão de estrangeiros: discursos pronunciados na Câmara dos Deputados, nas sessões de 29 de novembro e de 14 de dezembro de 1912. São Paulo: Espindola \& Co., 1913. Disponível em: <http://www.ebooksbrasil.org/eLibris/gordo.html>.

12 GORDO, Adolpho. A expulsão de estrangeiros... Op. cit.

13 Dizia Gordo: “[A República Argentina] foi forçada depois dos bárbaros e estúpidos atentados anarquistas em uma Igreja da Capital, no Teatro Colón e depois do assassinato do Chefe de Polícia, a decretar, quase que em momentos, a lei de 23 de Novembro de 1902, que denominou: "lei de residencia'”, quando talvez quisesse fazer referência à Lei de Defesa Social, aprovada em 1910. 
Gordo criava um panorama marcado por uma grave situação política em um país próximo e silenciava sobre o incômodo fato de que os atentados mencionados ocorreram depois da aprovação da elogiada lei. Além disso, Gordo aproveitava para destacar que o contraste da debilidade da lei brasileira levava os criminosos internacionais a quererem casar-se com uma mulher brasileira e transformava o Brasil em "refúgio de anarquistas e fomentadores de desordens", atraindo "vagabundos, mendigos, caftens, anarquistas e bandidos profissionais, expulsos de toda a parte". ${ }^{14}$

O deputado paulista podia não ser nada rigoroso quando se tratava de datas, mas fazia eco das palavras de seu par argentino, durante as discussões da Lei de Defesa Social, em 1910: ${ }^{15}$

Este país tem o direito fundamental, senhor deputado, reconhecido por todas as constituições do mundo, de se defender por meio de leis de preservação social dos perigos exteriores importados, seja de uma epidemia, seja de um ladrão reconhecido, seja de um condenado por um tribunal de justiça, de um anarquista, de uma prostituta ou de um cáften $[. . .]^{16}$

O deputado argentino completava, agregando um tom mais explicitamente racista, com a esperança de que a medida repressiva ajudasse a criar "bases étnicas depuradas" para a formação da raça argentina. O tom podia não ser muito comum no Brasil, mas o uso de argumentos científicos e higiênicos para fundamentar políticas imigratórias e formar a "uma boa raça futura" não era nada estranho aos brasileiros. Assim como tampouco eram estranhas as referências aos outros exemplos civilizados do mundo, a noção da expulsão como um direito fundamental de defesa da soberania e o conceito restringido e naturalizado da nacionalidade ameaçada pelos tais diversos "perigos exteriores importados".

Tanto no debate de 1910 na Argentina como no de 1912 no Brasil, o anarquismo era articulado como ameaça principal. Às vezes, no entanto, ele aparecia

14 GORDO, Adolpho. A expulsão de estrangeiros... Op. cit.

15 Sobre a Lei de Defesa Social, que era mais diretamente dirigida contra manifestações anarquistas e buscava impedir a entrada de militantes expulsos, ver SURIANO, Juan. Trabajadores, anarquismo y estado represor, p. 19.

16 O deputado em questão, nacionalista conservador, foi ministro plenipotenciário no Brasil na década de 1910. Deputado Ayarragaray, Diario de Sesiones de la Cámara de Diputados, junio de 1910, p. 325-326, citado em VILLAVICENCIO, Susana (Ed.). Los contornos de la ciudadanía, p. 203. Cf. KOZEL, Andrés. En torno a la desilusión argentina. Varia Historia, v. 23, n. 38, 2007. 
combinado a outras ameaças mais difusas, que se opunham "à segurança nacional e à ordem pública”. Assim, as referências a caftens, ladrões, mendigos e bandidos, juntamente com os anarquistas, reuniam diversas formas de não trabalho (assalariado) sob uma mesma denominação - indesejáveis - que ganhava, então, sentidos morais e políticos. Estudos recentes vêm mostrando que a amplitude dos conceitos empregados nesses debates e na própria letra da lei foi trasladada a sua aplicação. Nos dois países, as medidas de expulsão afetaram muitos outros estrangeiros além daqueles que foram acusados de anarquismo, como se notam nos pedidos de habeas corpus impetrados em nome dos afetados.

Frequentemente, um pedido de habeas corpus era a única possibilidade de frear um procedimento que se caracterizava pela celeridade e por deixar margens mínimas de ação por parte dos acusados. Mas nisso havia diferenças importantes entre as duas legislações. Como observou Giampetro Bonfá, a lei brasileira de 1907 não só reconhecia o tempo de residência como uma limitação à prerrogativa de expulsão (o que não acontecia no caso argentino), como também previa sempre algum tipo de recurso por parte do estrangeiro afetado, fosse em face do próprio Poder Executivo ou do Poder Judiciário. ${ }^{17}$ A questão era complicada, porque a expulsão não era uma pena; era uma medida administrativa em defesa da soberania nacional. Devia ser sumária, e consistia em um decreto de expulsão emitido pelo Poder Executivo. Uma vez emitido o decreto, o expulsado tinha três dias para deixar o país. ${ }^{18}$ Assim, era comum que, na consideração dos pedidos de habeas corpus, o Poder Judiciário nos dois países tendesse a respaldar a legislação, afirmando a constitucionalidade do ato de expulsão sem a possibilidade de acusação e julgamento nos termos da lei. Isso não quer dizer que alguns juízes tenham se declarado incompetentes para julgar os pedidos de habeas corpus ou

17 Esse autor argumenta que a lei de 1907 na verdade serviu para limitar (por exemplo, com o artigo sobre o tempo de residência) a ação arbitrária do Poder Executivo dos anos anteriores, exatamente por sua preocupação em ser constitucional e legal. Muito diferentes foram as modificações de 1913 e a lei de 1921, que também tinha o sentido de limitar a entrada de indesejáveis. BONFÁ, Rogério Luis Giampetro. "Com lei ou sem lei", cap. 2 e p. 133; MENEZES, Lená Medeiros de. Os indesejáveis, p. 187-219. A jurisprudência brasileira começou a se formar rapidamente depois da aprovação da lei de 1907. Ver Decisions concerning expulsion of foreigners from Brazil. The American Journal of International Law, v. 3, n. 2, p. 496-505, 1909. Sobre a jurisprudência argentina, ver FERREIRA, Marcela Aspell de Yanzi. Expulsión de extranjeros. La ley 4144 "de residencia" y la jurisprudencia de la Suprema Corte de Justicia de la Nación. Revista de Historia del Derecho, n. 15, 1987.

18 BONFÁ, Rogério Luis Giampetro. Com lei ou sem lei, p. 117-154. 
mesmo tenham julgado a favor dos indiciados, muitas vezes para frear a esfera de ação da polícia. ${ }^{19}$

Os procedimentos de expulsão eram bem diferentes nos dois países. Na Argentina, as Divisões Especiais da Polícia Federal eram responsáveis por realizar os procedimentos contra os suspeitos. Quando a investigação era concluída, o ministro do Interior assinava o decreto de expulsão, que podia ser coletivo. ${ }^{20} \mathrm{O}$ decreto voltava à polícia, que devia encarregar-se de garantir a saída dos indesejáveis.

No Brasil, o processo de expulsão também estava nas mãos da polícia. Mas as instruções para a execução da lei estabeleciam alguns procedimentos específicos, porque, além da ampla e indefinida figura de ameaça à "segurança nacional", a lei também mencionava, especificamente, como motivos da expulsão, "a vagabundagem, a mendicidade e o proxenetismo competentemente verificados". ${ }^{21}$ Quanto às duas primeiras modalidades, $\mathrm{o}$ auto de prisão em flagrante era prova suficiente para fundamentar a expulsão. Mas, no caso do proxenetismo, era necessário um inquérito policial que reunisse "documentos de reconhecida força probatória", ou pelo menos a declaração de "duas testemunhas insuspeitadas que afirmem a verdade do fato". ${ }^{22} \mathrm{O}$ inquérito era levado ao ministro da Justiça e as portarias de expulsão eram emitidas, em geral, para casos individuais.

$\mathrm{Na}$ prática, era bem provável que muitos estrangeiros fossem expulsos da Argentina e do Brasil por meios sumários e sem muito (ou qualquer) procedimento formal ou registro. ${ }^{23}$ As rotinas de vigilância policial nos portos e o tratamento policial dispensado a certos tipos de estrangeiros reiteram que a

19 Em uma análise comparada em 1942, Irizarry y Puente refere-se a uma ampla jurisprudência brasileira, em contraste com o caso argentino, mas sempre a tendência era de respaldar o princípio da prerrogativa do Poder Executivo de expulsar "indesejáveis". PUENTE, J. Irizarry y. Exclusion and expulsion of aliens in Latin America. The American Journal of International Law, v. 36, n. 2, p. 252-270, 1942. Héctor José Tanzi se refere ao notório caso Macias como sendo a primeira vez em que a Corte Suprema argentina se manifestou favoravelmente sobre a constitucionalidade da lei de residência. TANZI, Héctor José. Historia ideológica de la Corte Suprema de Justicia de la Nación (1930-1947). Iushistoria, Revista electrónica, n. 1, p. 39, 2004.

20 Ver FERREIRA, Marcela Aspell de Yanzi. Expulsión de extranjeros, p. 10-12.

21 MENEZES, Lená Medeiros de. Os indesejáveis, p. 207.

22 MENEZES, Lená Medeiros de. Os indesejáveis, p. 207.

23 Medeiros afirma que os anarquistas só começaram a ser expulsos por meio de processos a partir do movimento insurrecional de 1918. Ver MENEZES, Lená Medeiros de. Os indesejáveis, p. 211. Para uma discussão da repressão do movimento anarquista no período anterior, ver LEAL, Claudia Baeta. Pensiero e Dinamite: anarquismo e repressão em São Paulo dos anos 1890. Tese (Doutorado 
prática da expulsão como medida policial era comum muito antes da aprovação dessa legislação. Para muitos contemporâneos que denunciavam as violências policiais, podia não ser muito relevante que alguns casos terminassem registrados em papel e outros não, já que eram medidas ilegítimas em qualquer circunstância. No entanto, a existência de registros em certos casos abre para os historiadores possibilidades significativas, embora limitadas, de investigar os caminhos de legitimação das expulsões e as vidas daqueles que foram seus alvos. ${ }^{24}$

Assim, quando contrastadas, as legislações argentina e brasileira chamam a atenção para a preocupação com o formato judicial dos procedimentos requeridos para a expulsão no segundo caso. Enquanto na lei argentina os motivos de expulsão eram apresentados de forma geral, na lei brasileira as várias razões eram previstas e explicitadas. Principalmente, a legislação nacional previa mecanismos de prova dependendo do caso, e a expulsão era sempre individual. Se esse procedimento criou conjuntos documentais bem diferentes, também criou um problema no caso brasileiro: como foi dito, ao ser prerrogativa do Poder Executivo, a expulsão jamais poderia ser uma pena, já que era uma medida administrativa. Mas o lenocínio e a vagabundagem, causas da expulsão, eram, respectivamente, um delito e uma contravenção para os quais havia ações legais previstas pelo Código Penal. A forma judicial dos procedimentos de expulsão, assim, levava os funcionários policiais a tomar praticamente as mesmas medidas para iniciar um inquérito que levaria a um processo judicial ou um inquérito que terminaria com uma portaria ministerial de expulsão, sem a interferência de qualquer juiz. O caráter individual da expulsão brasileira, a exigência de duas testemunhas e o formato de inquérito iniciado com um auto de flagrante transformavam os procedimentos de expulsão em praticamente uma investigação de contravenção.

Essas características reforçavam o papel central do não trabalho como um elemento recorrente das acusações. Especificamente, no caso da acusação de lenocínio, a prova testemunhal era elemento decisivo. ${ }^{25}$ A exigência de duas tes-

em História) - Instituto de Filosofia e Ciências Humanas, Universidade Estadual de Campinas, Campinas, 2006.

24 Rogério Bonfá caracteriza essa percepção, que é trasladada para a historiografia como uma interpretação sobre a Primeira República como um "regime de exceção legal", expressão de Paulo Sergio Pinheiro em Estratégias da ilusão: a revolução mundial e o Brasil, 1922-1935. São Paulo: Cia. das Letras, 1995. Ver BONFÁ, Rogério Luis Giampetro. Com lei ou sem lei, especialmente p. 85-88. 25 MENEZES, Lená Medeiros de. Os indesejáveis, p. 207. 
temunhas acusatórias para embarcar um estrangeiro em um navio dava lugar a acusações de todo tipo de manipulação e perseguições pessoais nas delegacias, reiteradas em pedidos de habeas corpus. Esse aspecto era reforçado com a variação e a simultaneidade das acusações: um estrangeiro podia ser acusado de ladrão, proxeneta e vagabundo em um mesmo inquérito que concluía com a portaria de expulsão.

A marcada preocupação em conferir uma forma judicial aos procedimentos do Poder Executivo no caso brasileiro, em contraste com o caso argentino, reforça a necessidade de se repensar o que nos dizem as formas a respeito de ações consideradas pelos contemporâneos e pela historiografia como marcadas exclusivamente por uma inspiração autoritária e arbitrária. As formas podem ser reveladoras de conflitos pela legitimação pública de certas medidas, e também podem ter outras utilidades, como a de intervir em favor das ações policiais em seus reiterados conflitos com o Poder Judiciário sobre os limites de sua esfera de ação. Em outras palavras, no caso do Brasil, a legislação de expulsão pode ter servido para legitimar tudo aquilo que acontecia portas adentro das delegacias e que terminava aparecendo como um "inquérito policial” - só que com a vantagem de não depender da interferência de incômodos funcionários e procedimentos judiciais. ${ }^{26}$

Outro efeito "colateral" do formato adotado no Brasil se relaciona com o papel da polícia na criação e na divulgação de certos sentidos comuns sobre o cáften, principalmente, a ideia de que o lenocínio era um fenômeno estrangeiro. Os processos de expulsão de proxenetas analisados por Lená Medeiros de Menezes indicam que o perfil geral do estrangeiro suspeito continuou sendo o mesmo daquele afetado pelas expulsões anteriores à lei de 1907 e o mesmo que aparecia nos processos judiciais regulares de lenocínio. Assim, o grande número de homens provenientes da Europa centro-oriental, que se declaravam como negociantes de todo tipo, em especial de roupas e tecidos, e o de homens que vinham de uma rota suspeita pela América do Sul são elementos que, antes de ser consi-

26 De certo modo, assim, a lei de expulsão parecia funcionar como uma Lei Alfredo Pinto para os estrangeiros. Aprovada em 1899, conferia amplos poderes à polícia para julgar contravenções de vagabundagem, restringindo a interferência judicial. Mas, nesse caso, tratava-se de um inquérito policial, enquanto a expulsão de estrangeiros era diretamente uma medida exclusiva do Poder Executivo. Sobre o caráter autoritário da Lei Alfredo Pinto, ver SANTOS, Myrian Sepúlveda dos. Os porões da República: a colônia correcional de Dois Rios entre 1908 e 1930. Topoi, v. 7, n. 13, especialmente, p. 456, jul./dez. 2006. 
derados como evidências da organização do tráfico ou do perfil dos traficantes, devem ser analisados no contexto de sua produção como provas policiais. ${ }^{27}$

As idas e voltas de homens e mulheres suspeitos de proxenetismo entre ambos os países, então, não podem ser tomadas pelos historiadores da mesma maneira que as consideravam os funcionários policiais - como provas da existência de um tráfico de mulheres europeias. Seus movimentos talvez sejam mais úteis se forem considerados como uma via para conhecer melhor os termos de certas redes sociais tecidas entre grupos de imigrantes, na medida em que trazem para um primeiro plano as expectativas e os conflitos provocados pela dimensão moral de certos arranjos e estratégias de sobrevivência.

\section{Um passado em Buenos Aires}

Os registros produzidos pela polícia brasileira para obter uma portaria de expulsão de estrangeiros podem iluminar uma zona de ambiguidades e fronteiras pouco definidas entre inquéritos formados para fundamentar um processo judicial e aqueles que terminavam em uma portaria de expulsão. Por que alguns suspeitos de caftismo foram judicialmente processados enquanto outros foram expulsos? Em geral, os processos de expulsão por lenocínio eram iniciados contra homens, muitos dos quais desembarcavam no Rio de Janeiro em busca de mulheres suas conhecidas ou amantes que haviam chegado antes por diversas razões. No entanto, entre os primeiros registros de expulsão produzidos pela polícia carioca, encontram-se alguns movidos contra mulheres que viviam na chamada "zona das ladras", as rótulas da região das ruas de São Jorge e da Alfândega. ${ }^{28}$ Para

27 A historiadora Lená Medeiros de Menezes afirma, com base em mostra de 194 expedientes de expulsão de caftens: "Tomado o conjunto global, um peso significativo marca a presença de caftens oriundos da Rússia, Polônia e França, demonstrando que o Rio de Janeiro estava profundamente envolvido no tráfico organizado em nível internacional, fato que tinha sua maior comprovação na total inversão do peso destas nacionalidades nas tendências gerais da imigração para o Rio de Janeiro." MENEZES, Lená Medeiros de. Os indesejáveis, p. 163. Ver também MENEZES, Lená Medeiros de. Os estrangeiros, p. 80.

28 São parte dessa iniciativa os papéis de expulsão de Scharlota Meir, IJJ7 - 147, 1907, e de Augusta Liffe, IJJ7 - 131, Série Interior - Estrangeiros, Arquivo Nacional. Todas as citações de processos de expulsão daqui em diante pertencem a esse fundo documental. Junto ao inquérito de Meir, está também um pedido de habeas corpus em nome de Bertha Brockman, presa no mesmo dia, pela mesma razão. Todas foram defendidas por Evaristo de Moraes. 
explicar sua opção pela medida da expulsão e não por um processo judicial por roubo, furto ou lenocínio, o delegado confessava no relatório do inquérito:

Tão frequentes têm sido as queixas contra ela recebidas, que, impossibilitado de agir criminalmente por carência de testemunhas [e] dada a natureza especial dos delitos que lhe são imputados [...] [não tinha outra opção que a de solicitar a expulsão]. ${ }^{29}$

Desde a aprovação da lei em janeiro de 1907, assim, o delegado contava com uma alternativa para casos difíceis, para os quais não havia testemunhas dispostas a realizar acusações. Bastava reunir as declarações de funcionários policiais e de algum vizinho e com isso livrar-se rapidamente do problema, nesse caso, da mulher austríaca que vinha fazendo a vida há anos naquela zona. Assim, foi um farmacêutico vizinho que declarou não ter dúvidas de que ela exercia o lenocínio, "pois aluga cômodos a outras mulheres por 14 mil réis diários". A seus olhos, essa seria a única explicação para que ela pudesse viajar para a Europa com frequência, o que chamava sua atenção. Essa mulher foi defendida por Evaristo de Moraes, que reagiu com a mesma celeridade da polícia, impetrando pedidos de habeas corpus a favor dela e de outras. Neles, acusava a polícia de perseguição contra algumas mulheres isoladas, instaladas há mais de cinco anos nas mesmas casas, e principalmente em um contexto em que a legislação brasileira não reprimia diretamente a prostituição. ${ }^{30}$ Mas essa e outra mulher presas no mesmo dia terminaram expulsas por portarias assinadas pelo ministro da Justiça em menos de 48 horas.

29 Relatório do delegado do $4^{\circ}$ Distrito Policial, $1^{\circ}$ de julho de 1907. Expulsão de Scharlota Meir, IJJ 7 - 147, 1907, Arquivo Nacional. A mesma explicação foi dada no caso de Augusta Liffe, caso trabalhado por MENEZES, Lená Medeiros de. Os indesejáveis, p. 242.

$30 \mathrm{O}$ advogado socialista Evaristo de Moraes ficou conhecido por sua defesa de legislações sociais na Primeira República, atuando junto a diversas organizações de trabalhadores, também se popularizando como defensor de autores de crimes passionais. Em suas memórias, conta que se aproximou da "causa das prostitutas" por pena diante de mulheres que receberam ordem policial de mudança de suas casas em 1896. Depois disso, começou a escrever contra iniciativas de regulamentação da prostituição e também contra as práticas de policiamento que caracterizavam o caso carioca. Também defendeu homens judeus acusados de caftismo no período por meio de habeas corpus e em processos de lenocínio. Ver MORAES, Evaristo de. Ensaios de patologia social: vagabundagem, alcoolismo, prostituição, lenocínio. Rio de Janeiro: Leite Ribeiro \& Maurillo, 1921; MORAES, Evaristo de. Reminiscências de um rábula criminalista. Rio de Janeiro/Belo Horizonte: Briguiet, 1989. Ver MENDONÇA, Joseli Nunes. Evaristo de Moraes. Tribuno da República. Campinas: Unicamp, 2007. especialmente p. 65-89; e SCHETTINI, Cristiana. "Que tenhas teu corpo", especialmente p. 31-35. 
Esses primeiros meses de vigência da lei sugerem que os delegados montavam casos de expulsão com os mesmos argumentos que costumavam usar para criar um processo de lenocínio, em especial com a ideia de exploração fundamentada na cobrança de aluguéis exorbitantes das prostitutas. ${ }^{31} \mathrm{~A}$ diferença, então, estava na sinceridade desse delegado: a opção de expulsar era mais rápida e parecia ser mais eficaz, quando por diferentes razões era difícil montar um processo criminal de lenocínio. ${ }^{32}$

Uma vez que estavam livres da obrigação de reunir provas de valor judicial, os inquéritos de expulsão de estrangeiros foram se transformando em um âmbito de formulação e de reverberação de estereótipos sobre a figura do cáften estrangeiro. Foi assim quando o alemão conhecido por muitos nomes, Pascoal Delgiso, Abraham Schuman, Beker e Adolfo Clemente, foi preso pelo inspetor da polícia marítima dentro do navio francês que o trazia de Montevidéu, aparentemente expulso do Uruguai. O alemão viajava acompanhado por duas mulheres. Uma vez preso, o homem foi acusado de ser cáften, e as mulheres que o acompanhavam, identificadas como suas escravas por duas testemunhas reunidas pelo delegado da $3^{\text {a }}$ Delegacia Auxiliar, mas que não conheciam nem ele nem elas. ${ }^{33}$ Talvez, em outros tempos, um homem expulso de um país vizinho, suspeito de cáften, acompanhado de duas mulheres, simplesmente não tivesse seu desembarque autorizado pela polícia portuária. ${ }^{34}$ Mas a decisão de desembarcá-lo, prendê-lo e iniciar os procedimentos de expulsão reforçou a ideia de que a passagem prévia

31 Para uma análise da cobrança de aluguéis exorbitantes como motor de processos de lenocínio, ver SCHETTINI, Cristiana. "Que tenhas teu corpo", cap. 1.

32 Em vários outros casos, a acusação era intercambiável entre ladrões, proxenetas, anarquistas. O recurso também era empregado pela polícia argentina. Para exemplos, ver SCHETTINI, Cristiana. Viajando solas: prácticas de vigilancia policial y experiencias de prostitución em la América del Sur. In: BRETÓN, Jorge Trujillo (Org.). En la encrucijada. Historia, marginalidad y delito en América Latina y los Estados Unidos de Norteamérica, siglos XIX y XX. Guadalajara: Universidad de Guadalajara, 2010. p. 331-353.

33 Expulsão de Paschoal Delgiso, IJJ7 - 148, 1907, em especial o Auto de Declarações da testemunha Emyidio Jeronimo da Silva, "empregado público", que disse que o acusado circulava entre o Brasil e a República Oriental em busca de suas escravas (a palavra escrava foi sublinhada).

34 Para uma discussão sobre a ação da polícia portuária e para o problema do desembarque de caftens expulsos de países vizinhos, ver SCHETTINI, Cristiana. "Que tenhas teu corpo", cap. 2, e Viajando solas. Ver, também, GALEANO, Diego. Las conferencias sudamericanas de policías y la problemática de los delincuentes viajeros, 1905-1920. In: BOSHOSLAVSKY, Ernesto; SCHETTINI, Cristiana; CAIMARI, Lila (Orgs.). La policía en perspectiva histórica: Argentina y Brasil (del siglo XIX a la actualidad). Buenos Aires: El Autor, 2009. (CD-Rom). 
por Montevidéu, a companhia de mulheres e as viagens do implicado à Europa, tal como também havia ocorrido com Meir, eram elementos que confirmavam a suspeita de caftismo.

Em vez de considerar esses elementos como provas da existência de redes internacionais de traficantes, tal como fez o delegado, é fundamental inseri-los na lógica de atribuição de identidades por parte dos funcionários policiais brasileiros diante de uma complexa circulação de estrangeiros pelas fronteiras sul-americanas. Os sentidos desses deslocamentos internacionais e das relações entre esses homens e as mulheres que os acompanhavam podem não ser exatamente os mesmos para os envolvidos e para os funcionários policiais.

Estrangeiros com passagens prévias por Montevidéu ou Buenos Aires, com viagens reiteradas a Europa e estabelecidos há pouco tempo no Rio de Janeiro compunham um perfil frequente do cáften na documentação brasileira. Quando o francês Paul Gastaldi foi preso em 1917, o inspetor de Investigação e de Segurança Pública do Distrito Federal informou ao terceiro delegado auxiliar que ele era conhecido em Montevidéu e em Buenos Aires como "cáften e ladrão". Não havia condenação judicial, como tampouco houve nessa prisão no Rio de Janeiro, em que a declaração mais comprometedora foi a do agente de polícia, que disse conhecê-lo porque há mais ou menos um ano ele vinha "frequentando sempre os mesmos lugares suspeitos e convivendo com meretrizes". ${ }^{35}$ Significativamente, ao contrário de outros inquéritos policiais, esse foi diretamente intitulado "Autos do processo de expulsão de Paul Gastaldi", e, em outra parte, "Procedimento para expulsão”. Já era 1917, o Supremo Tribunal Federal havia confirmado a constitucionalidade das medidas de expulsão, e talvez o terceiro delegado auxiliar estivesse mais seguro de sua tarefa de expulsar indesejáveis. Assim, o "processo de expulsão", como medida administrativa, vai estabelecendo suas diferenças com o processo judicial.

Se, em muitos casos, a única acusação contra os estrangeiros suspeitos era conformada por indícios genéricos de que "conviviam" com prostitutas, sem mais precisões, em outros casos, as "escravas" tinham uma participação mais ativa, contribuindo para revelar alguns outros sentidos dessas histórias, talvez menos compreendidos pelos funcionários policiais. Tudo indica, por exemplo, que a investigação contra o argelino Maurice Alban, chegado de Buenos Aires no 
começo de novembro de 1913, tenha sido resultado da iniciativa de sua esposa, Fernanda Alban, que já se encontrava no Rio de Janeiro há mais ou menos 10 meses. Como outras mulheres que acusavam seus amantes, maridos ou namorados de caftismo, Fernanda contou que seu marido queria "forçá-la ao meretrício" nem bem haviam chegado a Buenos Aires. Ela, "iludindo a vigilância" do esposo, fugiu para o Rio de Janeiro. Fernanda não diz como vivia no Rio de Janeiro, mas se definia como "artista", tal como a outra mulher francesa que vivia na mesma pensão que ela na rua Bento Lisboa, e assim era reconhecida pelo italiano que residia na mesma pensão. Ela compareceu à delegacia armada de provas contra seu marido: cartas ameaçantes recebidas enquanto estiveram separados e também os recibos de remessas constantes de dinheiro feitas para ele durante o primeiro semestre de 1913.

Pelas cartas, descobrimos que Maurice Alban era concessionário de uma casa francesa de vinhos finos e conhaques em Buenos Aires. As missivas vinham cheias de insultos, que o tradutor se eximiu de traduzir do francês, e revelam um marido crescentemente furioso com as promessas descumpridas de retorno por parte de sua mulher. Já sem acreditar que ela não tinha dinheiro para voltar a Buenos Aires, ele vocifera que ela deveria ter deixado de pagar a pensão, ou vendido sua pulseira para conseguir comprar a passagem. Enquanto a cada carta o marido argelino alimentava sua ira, vão aparecendo indícios do que foram esses meses para Fernanda no Rio de Janeiro. A tal pulseira que ela não quis vender, por exemplo, parece ter sido o presente de um "amigo", o que deixou o marido ainda mais furioso:

eu desconfiava bem que tu não estavas só [...] e durante este tempo tu não me mandastes nada, é verdade que ele te pagava a pensão, e ele dormia contigo todas as noites, e ele passava os dias contigo, isto tu não me dicestes [sic], tu chamas isto um miché, eu chamo isto um gigolô, tu bem sabes como eu penso a este respeito [...] acabo de receber 740 pesetas, eu vou pagar o meu aluguel e as minhas dívidas. [...] tua vida no Rio foi um mistério para mim [...].

Em outra carta, as censuras continuam e vão revelando o sentimento de impotência que a distância de Fernanda provocava:

É realmente necessário que tu te aches bem com o tipo, para viver completamente com ele, e agora tu estás morando numa pensão de família!!!! Desde o tempo que tu estás com este tipo ele dorme todas as noites contigo e tu não achastes meio de 
me mandar 300\$000 por semana, que em cada carta tu me prometes, é preciso que tenhas muita ousadia para escrever-me assim, eu cheguei a te pedir dinheiro coisa que nunca fiz.

Enquanto, por alguma razão que nunca chegamos a conhecer, Maurice estava "preso" em Buenos Aires, sem poder viajar, Fernanda ia encontrando maneiras de sobreviver no Rio: muda para uma pensão familiar, encontra um homem com quem dorme e que paga suas contas, como muitas outras artistas relacionadas, por exemplo, com o teatro de variedades naqueles anos. ${ }^{36}$ Fernanda, assim, parece continuar ganhando a vida com a troca de relações sexuais por diferentes coisas - presentes, pagamento de suas contas, dinheiro. Mas, como o dinheiro nunca chegava a ele, Maurice desconfiava de que aquele "miché" estava mais para um "gigolô", função que deveria estar reservada a ele, o marido.

O precário equilíbrio encontrado por ela para manter-se a distância de Maurice se quebra quando ele finalmente parte rumo ao Rio de Janeiro em busca da mulher fugida. Mas Fernanda recorre à polícia e ao marco legal republicano, que permite que, em uma semana, o delegado consiga a portaria de expulsão de Maurice Alban. Diante dessa situação, o argelino termina embarcando voluntariamente de volta para Buenos Aires. Para o delegado e para os funcionários, Maurice é um “torpe explorador do lenocínio", e Fernanda é sua escrava. O fato de que Fernanda continue vivendo do comércio sexual, ainda que em sua versão mais elegante, só reforça o que as cartas e os recibos de dinheiro comprovam. Para ela, a criminalização do lenocínio no Código Penal republicano e a celeridade da lei de expulsão, juntamente com os conhecimentos que ela conseguiu travar (tanto com amantes quanto com companheiras de trabalho e de moradia), foram fundamentais para que ela soubesse que na delegacia de polícia encontraria aliados no conflito com seu marido.

Em suas declarações, Buenos Aires representa um passado do qual ela queria se afastar, deixando para trás seu marido abusador. A chegada ao Rio de Janeiro é acompanhada da expectativa de uma vida diferente: não necessariamente distante do trabalho sexual, mas, sim, de uma relação abusiva e da ideia da exploração de um cáften. Talvez essa francesa não tivesse consciência de que seu relato corroborava as imagens que circulavam com cada vez mais força sobre Buenos

36 SCHETTINI, Cristiana. Circuitos de trabalho no mercado de diversões sul-americano no começo do século XX. Cadernos AEL, v. 15, n. 27 (no prelo). 
Aires como centro do tráfico internacional de mulheres. Ao ser uma cidade que regulamentava a prostituição por meio de posturas municipais e um dos principais centros receptores de imigrantes europeus, a capital argentina era vista como o paraíso dos traficantes de brancas, visão consistente com o relato de Fernanda sobre sua vida entre as duas cidades. Em Buenos Aires, ela não parecia ter possibilidade de fugir de seu explorador, especialmente quando este era formalmente seu marido e ela já tinha a maioridade. ${ }^{37}$ Já no Rio, onde a prostituição não era regulamentada no âmbito da municipalidade, embora, sim, pela iniciativa policial, Fernanda podia não só viver de forma mais autônoma, mas também buscar proteção contra a perseguição do marido.

Histórias de mulheres como ela sugerem que o contexto coercitivo de uma investigação policial organizada para expulsar um estrangeiro podia conviver com a expectativa de que o Brasil significasse uma maior autonomia em relação a vínculos previamente estabelecidos. Essa expectativa dificilmente podia aparecer com mais ênfase do que na história da russa Sara Praigret, de 23 anos, residente em uma pensão de mulheres na praia da Lapa. Sara também havia percorrido um circuito similar ao de Fernanda: conhecera seu amante, o italiano Vicente Grassi, dois anos mais jovem que ela, em Buenos Aires. Nem bem havia chegado ao Rio, aparece Vicente, indo morar com ela. Previsivelmente, a presença do italiano começou a incomodar sua vida, já que ela gastava muito com ele, comprava suas roupas, e até chegou a empenhar algumas joias para sustentá-lo. A solução, pelo menos em sua declaração ao delegado, foi drástica:

[...] cansada de manter Vicente, consegui fazê-lo embarcar para Buenos Aires, em princípios do mês de dezembro findo; [...] para tal fim, viu-se forçada a pedir dinheiro emprestado à locatária do prédio em que reside [...] após a partida de Vicente, ela [...] enviou-lhe uma carta, dizendo-lhe que não voltasse pois não queria viver mais na sua companhia, que apesar disso Vicente, chegando a esta Capital, no primeiro ou dois do corrente mês, procurando em seguida a declarante [...]..$^{38}$

$37 \mathrm{Na}$ Argentina, a regulamentação da prostituição por posturas municipais supunha que as mulheres maiores de idade que se inscreviam o faziam por livre e espontânea vontade. Seguindo a tradição legal francesa, regulamentarista, o Código Penal só criminalizava a corrupção de menores. Assim, parecia ser mais difícil que uma prostituta pudesse empregar a justiça e a lei contra exploradores. Ver GUY, Donna. El sexo peligroso.

38 Auto de Declarações de Sara Praigret, Expulsão de Vicente Grassi, IJJ-140, 1913. 
Toda a investigação policial, assim, decorria do fato de que Vicente não se conformara com a carta de Sara e voltara ao Rio atrás dela. Todas as mulheres que moravam na casa da Lapa com Sara contaram a mesma história, acrescentando detalhes que sugeriam o incômodo que representava Vicente na vida de Sara. Ana Gold, a proprietária da pensão, por exemplo, relatou uma vez em que viu Sara dando-lhe dinheiro para que ele fosse passar uma noite em outra pensão e a deixasse em paz. Margarida Grin, outra russa, escutara uma vez em que Vicente insistia para que Sara lhe desse 30 mil réis, dizendo que "estava habituado sempre a ter dinheiro no bolso", mas também contava que ele a ameaçava com um revólver.

Como concluiu outra moradora da mesma casa, Sara não teve outra alternativa: "temendo que Vicente voltasse a explorá-la, resolveu apresentar queixa à polícia”. Novamente, recibos de remessas de dinheiro e de gastos em alfaiates, telegramas e as declarações de suas companheiras de casa e de vida foram suficientes para que Vicente terminasse sendo expulso em menos de 10 dias da denúncia de Sara.

Os indícios da experiência de Fernanda e de Sara, mulheres que continuaram exercendo o comércio sexual no Rio de Janeiro e provavelmente seguiram gastando dinheiro em seus vínculos com outros homens, evidenciam as limitações das percepções de contemporâneos e também da historiografia sobre as relações violentas a que estava submetidas as prostitutas europeias no período. Registros das experiências de trabalho e sociabilidade de mulheres como elas nos permitem pôr em questão as próprias linhas básicas das narrativas de tráfico de mulheres. Essas narrativas, com dimensões simbólicas muito atraentes e eficazes, tendem a reduzir toda experiência de imigração relacionada com o exercício da prostituição a uma dimensão exclusivamente coercitiva e violenta. Nesse sentido, as histórias de tráfico de mulheres tendem a apagar alguns dos aspectos centrais das experiências de muitas prostitutas no período, tais como as relações de sociabilidade e os contatos entre mulheres em diferentes cidades, a possibilidade de acumulação econômica e de "comprar" o afastamento de homens indesejáveis, a dimensão potencialmente liberadora de certos deslocamentos internacionais e, finalmente, a possibilidade de um uso absolutamente imprevisto da legislação de expulsão de estrangeiros. 
As referências por parte dos funcionários policiais cariocas aos antecedentes argentinos nas vidas dos caftens e das prostitutas chegaram a funcionar como um elemento acusatório aceitável, em parte porque essas referências tinham ressonâncias particulares em suas vidas. Assim, uma vida anterior em Buenos Aires e o reencontro entre pessoas conhecidas previamente envolviam a possibilidade de trabalhar em melhores condições, conhecer novos clientes, escapar de maridos abusivos, ou simplesmente buscar uma vida melhor, como tantos outros imigrantes. Para os policiais, no entanto, os indícios de uma vida prévia pareciam ser a prova indiscutível de que estavam tratando com indesejáveis desconhecidos e ameaçadores. Essa percepção policial talvez tenha contribuído também para a ideia de que o tráfico de mulheres se fazia por redes de traficantes que atuavam internacionalmente. Pelo menos nos casos identificados, essas redes parecem ser redes mais amplas de sociabilidade articulada em contextos migratórios, e não redes criminosas. ${ }^{39}$

Nesse mesmo sentido, a noção de exploração que vai aparecendo nesses processos parece ir adquirindo múltiplas dimensões para policiais, testemunhas, acusados e vítimas. Se em várias expulsões é a própria explorada que realiza a acusação e apresenta as provas, em outros casos, as mulheres se recusam a ser definidas como escravas. Em meados de 1909, a chegada de três homens russos, vindos de Buenos Aires, que não cessavam de receber visitas de prostitutas, chamou a atenção de muita gente. ${ }^{40}$ Chamada para depor, a russa Elisa Zilberstein declarou ao delegado que ela simplesmente foi visitar "uns patrícios seus" recém-chegados. Embora fosse "amiga" de um deles, esclarecia, "não era deste escrava". Os russos não chegaram a ser expulsos porque embarcaram voluntariamente para fora do país.

No mesmo sentido, o polonês Sender Nidzvedsky começou a ser vigiado de perto por um agente de polícia no verão de 1920 por ser casado com uma meretriz da rua do Núncio, que alugava rótulas a "umas pretas que são suas inquilinas". A meretriz em questão vivia com Sender e uma filha em outra pensão. Como

39 A ideia de redes criminosas é mais associada aos caftens judeus. Para estudos que relativizam essa visão, considerando as associações de prostitutas e caftens judeus como associações fundamentalmente mutuais, ver KUSHNIR, Beatriz. Baile de máscaras - mulheres judias e prostituição. Rio de Janeiro: Imago, 1996; e DEUTSCH, Sandra McGee. Crossing borders, claiming a nation: a history of Argentine jewish women, 1880-1955. Durham: Duke University Press, 2010. p. 105-120.

40 Expulsão de Max Bader, IJJ7 - 143, 1909. 
explicava o próprio agente, a meretriz "quando acaba de exercer sua profissão vem pernoitar [...] em companhia de Sender e sua filha". Isso fazia de Sender um suspeito de caftismo por não ter "ocupação de espécie alguma, passando os dias em casa tomando conta da criança.". $\mathrm{A}$ dona da pensão em que o casal vivia com sua filha explicou que a pequena era interna de um colégio em Botafogo, mas que estava de férias e, portanto, aos cuidados do pai.

Não podemos conhecer os acordos que sustentavam relacionamentos como esses, mas é evidente que em certos casos o exercício da prostituição não parecia ser incompatível com relações mais ou menos consensuais entre diversos tipos de casais. Se nos primeiros casos de expulsão de estrangeiros as testemunhas e os funcionários policiais consideravam que a exploração se caracterizava pelos altos aluguéis cobrados por donas de casas de prostituição a suas inquilinas, em grande parte dos processos que se seguiram era a ruptura de algum acordo, ou a conclusão de uma relação amorosa, o que levava muitas mulheres a acusar seus companheiros de "torpes exploradores da prostituição". Em outros casos, no entanto, acordos e arranjos de família e de trabalho pareciam ser considerados aceitáveis por parte das mulheres, que não acusavam seus amantes e maridos. Muitos homens ilustrados consideravam que isso era sempre prova do pânico que sentiam de seus exploradores, mas também sempre desconfiavam das acusações que elas realizavam. É preciso, então, afastar-nos de suas interpretações para encontrar suas margens de ação e seus usos da lei. ${ }^{42}$

Essas trajetórias de vida registradas de forma fragmentada como parte dos procedimentos requeridos pela lei de expulsão de estrangeiros revelam encontros de pessoas, interesses e histórias que contribuíram para consolidar certas caracterizações de cidades que eram, ao mesmo tempo, cenário e parte das experiências de vida de muitos homens e mulheres que iam e vinham pelos portos sul-americanos. Seus deslocamentos poderiam ter motivações variadas, mas, ao viajar, tornavam-se vulneráveis e suspeitos aos olhos dos funcionários policiais e no marco da lei de expulsão. O entrecruzamento entre essas trajetórias e seus

41 Expulsão de Sender Niedzvesky, IJJ7 - 146, 1920.

42 Era o caso de Viveiros de Castro, que afirmava que era "um fato psicológico bem conhecido o domínio, o terror que os caftens exercem sobre as prostitutas que exploram", ao mesmo tempo que um jornalista alertava contra o risco de que as denúncias de prostitutas contra seus caftens pudessem ser simplesmente "rancores de ex-amantes". Ver SCHETTINI, Cristiana. "Que tenhas teu corpo", p. 143-144. 
possíveis significados para os envolvidos com práticas cotidianas de controle social e de repressão a estrangeiros abre a possibilidade de contextualizar certas práticas de policiamento sobre uma variedade de trabalhadores, e, em meio a elas, as ações e influências exercidas por esses homens e mulheres no desenrolar dessa história. 